\title{
Discursos de pais e mães sobre a amizade em famílias com filhos adolescentes ${ }^{1}$
}

\author{
Márcia Stengel ${ }^{2}$ \\ Pontificia Universidade Católica de Minas Gerais, Belo Horizonte-MG, Brasil
}

\begin{abstract}
Resumo: As transformações na família contemporânea trouxeram mudanças significativas, especialmente nas relações entre pais e filhos. O discurso da amizade parece ser uma das estratégias utilizadas pelos pais para lidar com as especificidades da adolescência. Apresenta-se aqui esse discurso de pais de adolescentes sob três perspectivas: a relação entre pais e filhos, dos pais com os amigos dos filhos e entre irmãos. A partir de pesquisa qualitativa baseada na história de vida realizada com nove pais de adolescentes, casados e separados, de camadas médias, este artigo tem por objetivo debater como estas relações se dão, quais são suas possibilidades e limites. observa-se uma contradição entre os ideais de relação familiar e de amizade. Se por um lado a amizade pode facilitar o relacionamento paterno-filial, também pode mascarar possíveis conflitos, tanto entre pais e filhos quanto entre irmãos. Como os pais desejam manter a família unida e sem conflitos, buscam soluções que garantam sua intenção.
\end{abstract}

Palavras-chave: família, adolescentes, amizade, relações familiares.

\section{Fathers and mothers' discourses about friendship within families with teenagers}

\begin{abstract}
Contemporary family transformations brought significant changes, especially in parents and their children relations. Friendship discourse seems be one of the strategies used by parents do deal with adolescence specificities. Presents here this teenagers parents discourse by three perspectives: relationships between parents and sons, parents with theirs children's friends and among siblings. From the quality research based in life histories done with nine middle-class teenagers parents, in marital situation or not, this paper debates how these relationships happens, what are their possibilities and limits. There is a contradiction between what is the ideal of a family's relationship and that of a friendship. If, in one hand, friendship can make a parent-son relationship easier, on the other hand, it can mask possible conflicts, be it between parents and sons or among siblings. In order to maintaining the family together and without conflicts, parents search for solutions which guarantee their intention.
\end{abstract}

Keywords: family, adolescents, friendship, family relations.

\section{Discursos de padres e madres sobre la amistad en las familias con hijos adolescentes}

\begin{abstract}
Resumen: Cambios dentro de la familia contemporánea provocó significativas mutaciones, especialmente en las relaciones entre padres e hijos. Lo discurso sobre la amistad parece ser una de las estrategias utilizadas por los padres para las especificaciones de la adolescencia. Presenta-se acá dos discursos de padres de adolescentes en tres perspectivas: las relaciones entre padres e hijos, de los padres con los amigos de sus hijos y entre hermanos. De las investigaciones cualitativas con historias de vida realizadas con nueve padres de los adolescentes de las capas medias, aquí se debate como esta relación se da, sus posibilidades y límites. Hay una contradicción entre los ideales de relación de parentesco y amistad. Si la amistad puede facilitar la relación entre padres e hijos, puede enmascarar posibles conflictos, ya sea entre padres e hijos como entre hermanos. Como los padres desean mantener la familia unida y sin conflictos, buscan soluciones para su garantía.
\end{abstract}

Palabras clave: familia, adolescente, amistad, relaciones familiares.

A família vem sofrendo diversas transformações, contemplando sua estrutura e os papéis de seus membros e gerando, consequentemente, mudanças no exercício da parentalidade. Do final do século XVIII até os anos 1960, a família, chamada de moderna, fundava-se no amor romântico. Os adultos estavam a serviço do grupo familiar e das crianças, cumprindo funções distintas entre homens

\footnotetext{
${ }^{1}$ Este texto foi revisado seguindo o Acordo Ortográfico da Língua Portuguesa (1990), em vigor a partir de $1^{\circ}$ de janeiro de 2009. Este artigo é fruto de Tese de Doutorado defendida pela autora junto ao Programa de Pós-graduação em Ciências Sociais da Universidade do Estado do Rio de Janeiro, intitulada Tradições, contradições, transformações: A família na ótica de pais de adolescentes, orientada pela Profa. Dra. Cláudia Barcellos Rezende. A autora contou com bolsa da FAPERJ.

${ }^{2}$ Endereço para correspondência

Márcia Stengel. Av. Itaú, 525. CEP 30.535-012. Belo Horizonte-MG, Brasil.E-mail: marciastengel@gmail.com
}

e mulheres que visassem à felicidade do grupo. A instituição do casamento era valorizada, pois só ela era capaz de garantir a realização destes objetivos (Roudinesco, 2003; Singly, 2007).

A partir dos anos 1960, tem-se a família contemporânea, chamada de "pós-moderna" (Roudinesco, 2003) ou "moderna 2" (Singly, 2000). Ela atribui grande peso ao processo de individualização, tendo como elemento central os membros que a compõem. Nesta família, "as relações só são valorizadas quando realizam as satisfações proporcionadas a cada um dos membros da família" (Singly, 2007, p. 131). Neste sentido, ela unirá dois indivíduos em busca de relações íntimas, por uma duração relativa. Em consequência, há um aumento no número de divórcios e recasamentos, tornando a transmissão da autoridade mais problemática (Roudinesco). 
Na família pós-moderna não há mais um modelo singular ou com características únicas. Há uma gama de possibilidades legítimas para viver as relações afetivo-sexuais e as relações parento-filiais, podendo essas coexistir, colidir ou interpenetrar-se. Por isso, os pais não têm mais um modelo único a ser seguido, mas devem criar suas próprias formas de exercer a parentalidade.

Se já não há mais um padrão estabelecido, o exercício da parentalidade ganha novos contornos na fase da adolescência, na medida em que ocorrem modificações na família que demandam adaptação e flexibilidade das regras. Uma das razões é o fato de os filhos adolescentes levantarem uma série de questionamentos dos valores, crenças e regras até então vigentes no contexto familiar. Para lidar com esta situação, pais procuram modelos para pautar as relações com seus filhos, e entre os filhos. A amizade tem se apresentado como um modelo recorrente, sendo tomada como referência e, muitas vezes, ideal para o estabelecimento das relações familiares (Costa, 1997).

A amizade, na língua portuguesa, significa tanto um sentimento, caracterizado por afeição e simpatia, quanto uma relação específica. De acordo com os dicionários Houaiss (Houaiss, 2009) e Aurélio (Ferreira, 2009), o sentimento da amizade se estabelece geralmente por pessoas que não são ligadas por laços de parentesco ou relacionamento sexual. Vale dizer, a própria língua faz uma contraposição entre amizade e parentesco, ponto recorrente nos estudos sociológicos e antropológicos, que serão discutidos a seguir.

No pensamento ocidental moderno, a amizade foi naturalizada "enquanto sentimento ou preferência individual, dando origem a uma relação baseada também em escolhas singulares" (Rezende, 2002, p. 18). Nas ciências sociais, em geral, a amizade aparece em contraposição ao parentesco: no primeiro se localiza um caráter voluntário e igualitário e, no segundo, uma assimetria e determinação da relação entre os envolvidos.

Segundo Rezende (2002), alguns estudos sociológicos e antropológicos sobre a amizade podem ser congregados em um grupo representado por autores como Allan (1989), Cucó (1995) e Paine (1974), que partem de uma definição preestabelecida de amizade, com representações e significados mais ou menos fixos. Para eles, a amizade é uma relação privada e pessoal, de expressão de sentimentos e da individualidade, pautada na equivalência, na igualdade e na autonomia dos sujeitos envolvidos. Daí a ideia de que entre amigos se estabeleça uma relação afetiva, de escolha mútua, regulada por interesses comuns e com a valorização da lealdade e da fidelidade.

Uma ideia corrente no senso comum e que vai ao encontro dos estudos acima referidos é a de que "parente não se escolhe, se ganha". Ou seja, os indivíduos não têm a possibilidade de definir quem serão seus pais, filhos ou irmãos. A lógica presente nesta ideia é de que, por ser a relação estabelecida biologicamente, não há nenhum tipo de mediação dos sujeitos ali envolvidos, ou seja, esta relação estabelecer-se-ia "naturalmente". Por mais que não se esteja satisfeito com um parente próximo, resta aceitá-lo.

Se nas relações de amizade o discurso é de paridade entre os sujeitos, na relação familiar a hierarquia se faz presente, ainda que com diversas nuances. Tem-se, assim, uma distinção nos papéis desempenhados pelos membros da família, os quais implicam diferentes funções, responsabilidades, direitos e deveres.

No modelo da família tradicional, também chamada apropriadamente de hierárquica, há uma clara distinção dos papéis de acordo com o gênero e a geração. Em outras palavras, homem e mulher se percebem intrinsecamente diferentes, assim como pais e filhos. Desta forma, os pais têm autoridade sobre os filhos e mantêm com eles relações mais distantes e mais pautadas na hierarquia. Esse modelo familiar pode ser resumido em hierarquia, desigualdade e privilégios.

Do mesmo modo que a sociedade contemporânea ou individualista tenta romper com esse padrão hierárquico, a família igualitária também o faz e valoriza os indivíduos por suas singularidades e idiossincrasias. Pode-se dizer, portanto, que este modelo familiar decorre das transformações sociais contemporâneas. O princípio regulador das relações no interior da família igualitária é a equivalência, promovendo o relacionamento dos indivíduos a partir do ideal de igualdade e respeito, rompendo com a ideia que as categorias homem/ mulher e adulto (pais)/criança (filhos) sejam intrinsecamente diferentes (Coelho, 2007; Heilborn, 2004).

Nesse modelo de família igualitária, a possibilidade de amizade entre pais e filhos faz-se presente na medida em que o ideal ai é o de igualdade e respeito entre os membros. Assim, pode-se considerar que as relações de distanciamento, falta de diálogo e separação mais radical entre pais e filhos, que faziam parte da família hierárquica, são substituídas pela tentativa de um diálogo constante e aberto, caracterizando uma relação de amizade.

Apesar de haver estes dois modelos de família, o que se observa no cotidiano é que as relações familiares são mais complexas, ou seja, a família vivida é mais flexível e plural (Vaitsman, 1994) e as características de um modelo e de outro se mesclam de inúmeras maneiras, compondo famílias singulares. Desta forma, a amizade também figura com uma gama de formas possíveis para serem pensadas e vividas dentro das famílias.

Na família hierárquica, o princípio da autoridade é básico no estabelecimento da relação entre pais e filhos. Assim, filhos devem obedecer às ordens dadas pelos pais e reconhecer o lugar de cada um na família; vale dizer, lugar pautado na diferença. Se a autoridade é inquestionável nesse modelo familiar, o mesmo não se pode afirmar em relação ao modelo igualitário. Caso o princípio básico desse modelo fosse levado à última instância, a autoridade não existiria nessa família. Costa (1997) revela que, no modelo igualitário, os pais saem do seu papel tradicional para serem amigos dos filhos, deixando uma lacuna no lugar da figura da autoridade. 
Kehl (2003) reitera o argumento acima afirmando que a dificuldade dos pais em sustentar sua posição de autoridade responsável perante os filhos decorre de um sentimento de dívida com sua prole. Este sentimento advém da perda da consistência imaginária conferida pela tradição, ou seja, os pais "se veem na contingência de impor limites e transmitir idéias a seus filhos por conta e risco" (Kehl, 2003, p. 174). Ao perceberem que não oferecem aos filhos a família idealizada - patriarcal, tradicional -, sentem-se em dívida com eles e tornam-se incapazes do exercício da autoridade. Para Kehl (2003, p. 175, grifos da autora),

Deste lugar mal sustentado, é possível também que os adultos não compreendam em que consiste sua única e radical diferença em relação às crianças e adolescentes, que é a única ancoragem possível da autoridade parental no contexto contemporâneo. Esta é, exatamente, a diferença dos lugares geracionais.

Ao igualar os sujeitos, a amizade apaga a diferença geracional, apontada por Kehl como fundamental para o papel formador da família, ou seja, para o preparo dos filhos para as responsabilidades quanto às normas de convívio social.

As relações entre pais e filhos adolescentes, se tomadas em sua complexidade, podem ser tratadas como uma arena marcada por permanentes conflitos e negociações (Cicchelli, 2001). Nesta arena, a adolescência dos filhos implica em transformações nas relações familiares e num permanente jogo de valores. O discurso da amizade parece ser uma das estratégias utilizadas na família para lidar com as especificidades desta fase da vida. Desta forma, pretende-se discutir aqui esse discurso de pais de adolescentes sob três perspectivas: a relação entre pais e filhos, entre pais e amigos dos filhos e entre irmãos.

\section{Método}

\section{Participantes}

Foram realizadas nove entrevistas com pais e mães das camadas médias de Belo Horizonte-MG, em situação marital ou não, que tinham no momento da entrevista pelo menos um(a) filho(a) entre 14 e 19 anos. No total, foram entrevistadas cinco mães, sendo três separadas e duas casadas, três pais separados e um pai casado. Considerou-se como separados aqueles sujeitos que não viviam mais uma relação marital com a mãe ou o pai do(a) filho(a) adolescente, independente de estarem casados(as) novamente ou não. A divisão dos sujeitos em grupos de casados e separados deveu-se à necessidade de conhecer as dinâmicas e estratégias diferenciadas que podem ocorrer quando os filhos moram com o pai e a mãe conjuntamente ou apenas com um dos pais, mesmo que este(a) esteja recasado(a).

A seguir, descrever-se-á cada um dos entrevistados, identificados por nomes fictícios. Para facilitar a leitura, os pais e as mães separados receberam nomes com a letra $\mathrm{S}$ e os casados com a letra C. As informações sobre os entrevistados - idade, número de filhos, estado civil e outras - correspondem ao momento de coleta de dados.

Simone: 48 anos, nasceu e viveu até o casamento no interior de Minas Gerais. Completou o curso de Magistério e é proprietária de uma loja de varejo. Tem duas filhas (24 e 17 anos) e dois filhos (18 e 14 anos) e está separada do marido, mas ele continua morando na mesma casa, pois se encontra em uma situação financeira precária. Solange: nasceu há 47 anos no interior de Minas Gerais. Na infância, mudou-se com a família, de nível socioeconômico baixo, para Belo Horizonte. Com cerca de dez anos, foi morar com a avó e depois com uma tia no interior de Minas Gerais, onde passou sua adolescência. Ao final da adolescência voltou para Belo Horizonte e se casou aos 25 anos com um engenheiro, com quem tem duas filhas (uma de 20 e uma de 16 anos). Casou-se no civil e no religioso e o casamento durou 16 anos, estando divorciada há sete anos. Aos 30 anos, iniciou curso superior na área de ciências humanas e atualmente trabalha como professora universitária. Há 13 anos mantém uma relação estável com um homem de 36 anos, que teve início ainda durante seu casamento. Sara: é psicóloga, tem 42 anos, nasceu e morou sempre em Belo Horizonte. Casou-se com 22 anos, grávida, no civil e no religioso com um publicitário de 25 anos. Tem duas filhas, de 18 e 13 anos, com quem sempre morou. Seu casamento durou cerca de cinco anos e está divorciada há doze anos.

Cândida: 52 anos, está casada há 23 anos e possui duas filhas, de 19 e 16 anos. É decoradora, católica praticante, viveu toda sua vida em Belo Horizonte. Camila: 51 anos, dona de casa, nasceu no interior de Minas Gerais e morava na fazenda da família. Aos nove anos ficou órfã de mãe e assumiu o cuidado da casa e dos irmãos. Na adolescência mudou-se para Belo Horizonte com os irmãos e voltou para o interior após completar o ensino médio. É casada, tem duas filhas, de 17 e 14 anos, e há cerca de quatro anos voltou para Belo Horizonte.

Sílvio: 44 anos, é engenheiro, nasceu e viveu praticamente toda sua vida em Belo Horizonte. É separado da primeira esposa, com quem teve dois filhos, de 17 e 15 anos. Recasou-se com uma mulher divorciada, que tem dois filhos (de 10 e 7 anos), com quem tem um filho de 3 anos. Ele mora com a esposa, seus três filhos e os dela. Saulo: 47 anos, é engenheiro, nasceu no interior de Minas Gerais e na adolescência mudou-se para Belo Horizonte. Tem uma filha do primeiro casamento que, após morar com a mãe na casa dos avós maternos, há cinco meses mudou-se para a sua casa. Casou-se novamente há três anos com uma mulher 20 anos mais nova, com quem tem uma filha de um ano. Samuel: tem 41 anos e é divorciado há oito anos. Casou-se no religioso e no civil e tem um filho de 14 anos e uma filha de 12 que moram com ele. Trabalha com terapias corporais e atualmente está fazendo curso superior de música. 
Cláudio: 45 anos, nasceu e sempre viveu em Belo Horizonte. Seu pai faleceu quando tinha 1 ano de idade; morou com a mãe e um irmão mais velho. Completou o ensino médio e é funcionário público. Sua esposa, com quem se casou no civil e no religioso há 21 anos, tem 46 anos, é formada em psicologia e também trabalha como funcionária pública, o casal tem uma filha de 21 anos e um filho de 17 anos.

\section{Instrumento}

Foram realizadas entrevistas em profundidade com os sujeitos da pesquisa, na intenção de construir suas histórias de vida. As entrevistas foram realizadas entre janeiro e agosto de 2002 .

A entrevista de pesquisa é definida como uma interação verbal que permite a obtenção do discurso de sujeitos determinados sócio-historicamente. (...) É sobre a enunciação, correlata de uma determinada posição sócio-histórica, que são buscados os processos psicológicos e sociais concernentes ao problema pesquisado (Machado, 2002, p. 35).

História de vida é uma fonte de informação sobre a experiência subjetiva. Com ela, tenta-se cobrir o movimento completo da experiência de vida do indivíduo e, ao mesmo tempo, interpretar estas experiências. A história de vida é um recurso metodológico útil, pois permite explorar não apenas eventos, mas também motivações, reflexões, interpretações e emoções, além de possibilitar o testemunho do processo pelo qual o indivíduo constrói seu self.

A história de vida é, por definição, uma reconstrução a posteriori, que ordena acontecimentos que balizaram uma existência. Além disso, ao contarmos nossa vida, em geral, tentamos estabelecer uma certa coerência por meio de laços lógicos entre acontecimentos-chave (que aparecem então de uma forma cada vez mais solidificada e estereotipada), e de uma continuidade, resultante da ordenação cronológica. Através desse trabalho de reconstrução de si mesmo, o indivíduo tende a definir seu lugar social e suas relações com os outros (Pollak, 1989, p. 13).

Além disso, segundo Laville e Dionne (1999), a história de vida inscreve-se entre a análise psicológica individual e a dos sistemas socioculturais, permitindo captar a maneira como os indivíduos fazem a história e modelam e são modelados por sua sociedade. A aproximação de múltiplas biografias, ao abstrair temas dominantes, torna possível generalizar um tipo ao mostrar que certas biografias têm, apesar de todas as idiossincrasias, alguns elementos comuns (Friedlander, 1998).

\section{Procedimento}

\section{Coleta de dados}

Para chegar aos entrevistados, buscou-se indicações de várias redes de conhecidos para se obter uma diversidade maior do universo pesquisado. Com alguns sujeitos a entrevista foi realizada em dois encontros e com outros em apenas um, em suas residências, locais de trabalho ou consultório de psicologia. Esta diferença no número de encontros se deveu à disponibilidade de tempo que ofereciam ou pelo próprio desenrolar das entrevistas. Os diferentes locais são consequentes à indicação e disponibilidade dos entrevistados.

\section{Análise dos dados}

A análise do material foi feita na perspectiva da análise do discurso, que, como apontado por Vala (1986), é uma técnica privilegiada para tratar, no caso de histórias de vida, o material recolhido. Trata-se da

desmontagem de um discurso e da produção de um novo discurso através de um processo de localização-atribuição de traços de significação, resultado de uma relação dinâmica entre as condições de produção do discurso a analisar e as condições de produção da análise (Vala, 1986, p. 104).

A análise do discurso possibilita trabalhar com as cadeias associativas produzidas pelo entrevistado, assim como seus silêncios, lapsos, esquecimentos, reticências, erros. Por isso, esse instrumento de análise é rico e serviu bem para o propósito desta pesquisa.

As entrevistas foram recortadas em categorias a partir de duas formas de análise. A primeira foi uma análise transversal dos temas presentes nos corpus das entrevistas. A segunda abrangeu uma análise dos significados apreendidos nas estruturas das falas individuais. Neste trabalho serão priorizadas as análises relativas ao tema da amizade.

\section{Considerações éticas}

A pesquisa foi submetida ao Comitê de Ética em Pesquisa da Pontifícia Universidade Católica de Minas Gerais e aprovada (Protocolo ${ }^{\circ}$ CAAE-0105.0.213.000-11). Após o conhecimento dos objetivos da pesquisa e seus procedimentos, os sujeitos concordaram com a realização das entrevistas, com sua gravação e divulgação. Em respeito a preceitos éticos, nomes fictícios são utilizados para preservar a identidade dos sujeitos, assim como quaisquer dados que por ventura venham a identificá-los. 


\section{Resultados e Discussão}

\section{Amizade entre pais e filhos}

Apesar de não ter sido ponto específico de investigação nas entrevistas, os entrevistados não mencionaram estabelecer relações de amizade com seus pais. Alguns deles mencionaram ter estabelecido, no presente ou no passado, uma maior proximidade com um dos pais; em sua maioria, com a mãe. Entretanto, em nenhum momento eles manifestaram ser esse relacionamento uma amizade. Ao contrário, dizem que a relação com os pais é ou era pautada por papéis bem definidos e pela presença da autoridade.

Este dado é similar ao encontrado por Rezende (2002) ao pesquisar a amizade em dois grupos geracionais. No grupo mais velho, formado por pessoas entre 45 e 50 anos (faixa etária coincidente com a dos entrevistados desta pesquisa), o caráter obrigatório da família era um problema, com papéis severamente distintos e hierarquizados, não havendo espaço para a individualidade. Desta forma, pais não eram vistos como amigos.

Esse grupo geracional foi quem operou a transformação de um modelo hierárquico de família para um modelo mais igualitário. Os sujeitos deste grupo estabeleceram relações com seus pais pautadas na diferença, enquanto com seus filhos procuram concebê-las na igualdade. Se a relação é pautada na igualdade, a amizade pode ser a base do relacionamento familiar.

Todavia, entre os entrevistados desta pesquisa, ainda que o discurso seja de uma família igualitária, o que se observa na descrição do cotidiano é uma pluralidade de formas familiares que se encontram entre os polos do modelo hierárquico e do modelo igualitário. Evidencia-se aí uma assimetria, na medida em que a hierarquia entre pais e filhos está questionada e, no cotidiano, aparecem práticas hierárquicas, ainda que amenizadas para justificar esse discurso igualitário. Sara afirma:

A gente acaba se dando muito espaço pra filho, nessa relação de querer muito ser amigo, né? Essa relação de amizade, ela tem que ter um limite, né? A gente não pode fazer de filho amiguinha, né? Nem confidente. A gente tem que ter um, um limite pra não perder a autoridade (Sara).

A partir da declaração de Sara, pode-se retomar a literatura das ciências sociais discutida anteriormente, que aponta como uma das características de uma relação de amizade algum grau de igualdade entre amigos (Rezende, 2002). Vale dizer, a existência de hierarquias poderia inviabilizar a amizade. Por esta razão, a amizade só pode acontecer entre pais e filhos que vivam um modelo familiar mais igualitário. De outro lado, só na medida em que o adolescente consegue autonomia em relação aos pais é que se pode considerar a factibilidade de uma amizade entre eles, pois pais e filhos estariam num mesmo nível: a adultícia. Desta forma, se Sara estabelecesse com a filha uma relação de amizade propriamente dita e de igualdade, assim como se vivesse um modelo familiar igualitário, não caberia colocar a questão da autoridade. Pode-se levantar dois pontos para o fato de a entrevistada salientar a autoridade: ela a considera como sendo parte da relação materno-filial, importante para o seu bom desenvolvimento; ela aponta para o conflito decorrente da convivência de modelos familiares distintos.

Veja-se o caso de Simone, que sempre estabeleceu uma relação de cumplicidade com a filha mais velha desde criança. Ela conta que o ex-marido não gostava que saísse de casa e fizesse compras. Simone saía com a filha e estabelecia com ela o acordo de não contarem nada ao pai. Ela diz que a menina "já era minha companheira, já era minha amiga, ela já tinha cinco anos". Não seria exagero dizer que havia uma amizade com uma criança de cinco anos? Essa relação parece ter se estendido ao longo da vida de Simone e a filha é considerada pela mãe como uma grande amiga, alguém que sempre lhe dá apoio. Interessante notar que a filha assume em casa o lugar de mãe, pois dá ordens aos irmãos menores e à própria mãe. Essa postura da filha é salientada pela mãe e é motivo de queixa dos irmãos.

Peck e Manocherian (1995) chamam a atenção para o perigo de filhos adolescentes assumirem o papel do cônjuge ausente, tornando-se confidente do pai ou da mãe e, até mesmo, colocando-se no lugar de coprogenitor, principalmente se há irmãos menores. Então, se Sara achou que poderia perder a autoridade sendo tão amiga da filha, e por isso muda as bases da relação, o mesmo não parece ter acontecido com Simone, que faz da filha sua confidente.

Saulo aponta dois aspectos ao falar da amizade entre ele e a filha. $\mathrm{O}$ primeiro se refere à sua afirmação de que, às vezes, ele é "muito mais amigo dela do que pai". Ele explica que isto se deve ao fato de os dois conversarem muito e de ela lhe contar sobre os seus namoros e suas dúvidas profissionais. Ele diz que sua atuação é dar mais conselhos "do que atuar de uma forma repressiva". aqui Saulo mostra uma diferença entre amigo e pai: este pode repreender o filho, ou seja, exercer uma autoridade que não é possível no caso da amizade. Logo em seguida, o entrevistado diz que ser pai "é ter uma relação com uma pessoa que ela é indissolúvel, que aconteça o que acontecer a relação não se dissolve".

Segundo Rezende (2001), há uma perspectiva na compreensão das relações de amizade e de parentesco - discurso difundido na sociedade brasileira - em que um dos contrapontos é a duração destas relações. Para a primeira, considera-se que os vínculos podem ser finitos, até mesmo porque há uma escolha deliberada nesse relacionamento. No momento em que se percebe que alguém não corresponde mais ao que se deseja como amigo, simplesmente rompe-se com a amizade e busca-se novos amigos. A mesma lógica não é considerada para a relação familiar. Além de não se poder escolher quem será o pai, a mãe, o filho ou o irmão, também não se deve romper radicalmente com eles. Nessa lógica, 
pais e filhos poderiam ter uma amizade que estaria acima de tudo, pois não pode ser dissolvida.

Sílvio caminha na mesma linha que Saulo, considerando que a relação entre pai e filhos está pautada na amizade e na troca. Ele diz:

O pai em relação ao filho é aquele elemento que vai estar presente, né? Ao longo da vida até o momento que você inverte a situação, mas conte com o seu pai, o seu pai tá sempre do seu lado, o seu pai é seu amigo e muitas histórias da vida dele, muitos momentos dificeis virão ainda, né? (Sílvio).

Neste sentido, conversar mais com os filhos e saber o que acontece na vida deles é um desejo de Sílvio, pois isso é "característica de uma relação sólida, consistente e permanente, né? E de perpetuidade".

Rezende (2002) aponta como um traço da amizade a confiança e o ato de se compartilhar questões pessoais e íntimas. Desta forma, entre amigos, espera-se que haja uma troca de confidências, pressupondo-se uma confiança total. Um amigo não trairia a confiança e nem espalharia os segredos. Entretanto, há, muitas vezes, uma seleção daquilo que se conta a um determinado amigo ou a outro. Isso dependerá do grau de amizade, do tipo de segredo, entre outros aspectos. Para o amigo íntimo, aquele que é eleito como especial, pode-se contar tudo sem risco de perda da confiança. Esse parece ser o ideal colocado por alguns pais e mães entrevistados para o estabelecimento da relação com seus filhos, principalmente entre mães e filhas. Camila fala que "mãe é a companheira, é a amiga, é a confidente, acho que a pessoa que você mais tem de confiar é na sua mãe simplesmente". Simone expressa: "eu gostaria que fosse assim, como se fosse uma amiga, sabe? Essa amiga que uma sabe tudo da outra". Oliveira (2000) discute que as mães têm relações mais íntimas com as filhas do que com os filhos e tendem a se identificar mais com elas, o que se apresenta em alguns depoimentos.

Há uma contradição entre o ideal do amigo íntimo e as relações parentais, na medida em que pais e mães afirmam que não acreditam que seus filhos lhes contem tudo e, como diz Sara, "também não tem que contar mesmo não, sabe? Porque tem coisas que a gente tem que preservar". Esse elemento também está presente na fala de Cândida, quando afirma: "tem que ter uma privacidade". Esta contradição fica mais clara ainda nas conversas sobre relacionamentos afetivo-sexuais dos filhos. Esses não contam tudo aos pais, assim como os pais nem sempre querem saber de tudo, colocando limites na conversa. Um exemplo é quando uma das filhas de Solange começa a lhe contar detalhes de sua vida sexual com o namorado e a mãe pede que pare, explicando à filha que há diferenças naquilo que se narra para as amigas e para a mãe.

Um ponto chama a atenção. Rezende (2002) discute que uma das características da amizade é a reciprocidade. Ao longo das entrevistas, pais e mães dizem ser amigos dos filhos, mas o contrário não é afirmado, ou seja, eles não se referem aos filhos como sendo seus amigos. A única exceção é Camila, que afirma claramente que suas filhas são suas amigas e justifica que isso se deve ao fato de ela ser "muito aberta com elas". Simone levanta esta possibilidade com sua filha mais velha ao dizer que "eu acho que ela deve também me ter como uma amiga dela". A forma como ela coloca, no entanto, faz parecer que não tem certeza dessa amizade. Além disso, Simone estabelece uma relação peculiar com essa filha, como exposto em outro momento.

\section{A relação dos pais com os amigos dos filhos}

O desejo de ser amigo dos filhos não é apenas pautado pelo tipo de relação que se deseja estabelecer - uma relação de maior proximidade -, mas também aparece como uma forma de controle dos filhos. Uma queixa generalizada entre os entrevistados é a perda do controle dos filhos na adolescência, consequente à busca de autonomia dos jovens. Essa perda traz uma insegurança maior, pois os pais não sabem muito quem são as companhias dos filhos, o que eles fazem ou que lugares frequentam. Desta forma, ser amigo possibilita aos pais um conhecimento mais amplo da vida dos filhos, já que uma das ideias presentes neste discurso da amizade é de não haver segredos entre amigos. É também por essa lógica que os pais tentam ser amigos ou, pelo menos, ter um contato próximo com os amigos dos filhos, que se tornam bons informantes dos pais. Sara diz: "sempre fiz questão de conhecer [os amigos das filhas], de saber quem são, né? (...) Isso pra mim eu acho fundamental, né? Participar de certa forma, né?". Para tal, Sara incentiva que as filhas levem seus amigos em casa para estudar, por exemplo. Camila e Cláudio contam que "batem papo" com as amigas como forma de saber mais da vida dos filhos.

Entre as camadas médias urbanas brasileiras, a adolescência é percebida como um momento específico de muitas transformações na vida, modificando hábitos, gostos e o próprio posicionamento frente ao mundo (Pratta \& Santos, 2007). Os pais veem seus filhos num processo de transformações e apontam dificuldades em lidar com isso. O sentimento é de certo estranhamento e desconhecimento frente aos filhos (Macedo, Azevedo, \& Castan, 2004; Stengel, 2000, 2003). Manter contato com os amigos dos filhos possibilita aos pais conhecê-los melhor. Cláudio, por exemplo, descobriu que seu filho tinha um "xodó" com um livro que havia lhe dado; ele achava que o menino não se interessava pelo livro. Samuel começa "a ver um lado [dos filhos] que não conhecia, um jeitinho diferente de falar, um jeitinho diferente de ser, como é que eles estão se relacionando no meio da turminha ali, quem eles são ali naquele pedaço". Além do melhor conhecimento dos filhos, ele acredita que o contato com seus amigos possa influenciá-los nas suas relações de amizade, seja perguntando sobre um possível afastamento de um amigo ou incentivando a aproximação com um que ele julgue boa companhia e influência. 
A relação com os amigos dos filhos também proporciona a possibilidade de os pais ficarem mais perto dos filhos e/ ou passar mais tempo com eles, principalmente porque há uma queixa generalizada, entre os entrevistados, do afastamento dos filhos na adolescência. Samuel costuma levar amigos dos filhos para o clube ou para acampar como forma de incentivá-los a fazer programas conjuntos com ele. A mesma atitude é tomada por Cláudio, que joga futebol com os amigos do filho ou leva as amigas da filha ao teatro com ele e a esposa.

\section{Amizade entre irmãos}

O ideal da amizade não se atém apenas às relações entre pais e filhos, mas se estende aos irmãos. Há a ideia de que irmãos são grandes amigos ou, pelo menos, deveriam ser. Camila explicita isso ao dizer às filhas: "a única amiga que uma vai ter é a outra, uma vai ser a outra, que deverá ser a companheira de verdade, em todos os momentos. Porque amigo você tem, mas na hora da dificuldade, o amigo não aparece". Esse discurso de Camila é igual ao que Solange faz para as filhas quando elas brigam: "não tem ninguém melhor do que um irmão, uma mãe pra poder resolver os problemas da gente". Solange considera tão importante essa amizade entre as filhas que declara que, em relação a elas, sua única demanda é "a amizade entre as duas".

A amizade entre irmãos merece algumas considerações. A literatura na área da Psicologia, assim como o senso comum, salienta o ciúme e a rivalidade nas relações fraternas. Lembremos da dupla de irmãos mais famosos da história: Caim e Abel. Ao longo das entrevistas, pais e mães discorreram sobre brigas, competições e diferenças entre seus filhos, ainda que isso não seja considerado como algo que inviabilize as relações de amizade entre os irmãos. Por outro lado, os entrevistados sublinharam a importância da família e as várias estratégias utilizadas por eles para a manutenção de uma família perfeita, bem estruturada e feliz. Pode-se, então, pensar que a ênfase dada à relação de amizade entre os irmãos seja uma forma de driblar os possíveis ciúmes e rivalidades entre eles, mantendo, deste modo, a família unida e equilibrada. Se os irmãos forem amigos, os problemas entre eles não ocorrerão e a família ideal será perpetuada.

Os entrevistados acreditam que a amizade entre irmãos seja possível. A respeito disso, alguns disseram que são amigos de seus irmãos. Pode-se pensar que a favor da amizade fraterna está a ideia de que amigos devem ter maior afinidade de valores (Rezende, 2002). Se durante a socialização primária os pais tendem a transmitir os mesmos valores para seus filhos, pressupõe-se que a maneira de eles verem o mundo seja a mesma ou, pelo menos, afim. Vale pensar que, desta forma, a relação de amizade entre irmãos pode fluir muito mais "naturalmente", pois os sujeitos envolvidos já teriam afinidade por princípio. Apesar de apontarem diferenças entre os filhos, os entrevistados buscaram amenizá-las e salientar semelhanças.
Outro aspecto que pode facilitar a amizade fraterna é o fato de os irmãos se encontrarem em faixas etárias mais próximas, o que também propicia valores e interesses mais comuns e minimiza os conflitos geracionais. Desta forma, é como se essa afinidade garantisse uma relação de amizade duradoura e sólida, garantindo, consequentemente, a própria família.

Outro ângulo a ser considerado nas relações entre os irmãos articula-se com o aumento nos índices de separações e novas uniões. Kehl (2003, p. 169) propõe pensar esta nova família que se forma como tentacular, "que traz em seu desenho irregular as marcas de sonhos frustrados, projetos abandonados e retomados, esperança de felicidade das quais os filhos, se tiverem sorte, continuam a ser portadores". Com os vários tentáculos que as famílias vão adquirindo, o pátrio poder vai sendo distribuído entre os diversos adultos, o que produz uma tendência à formação de novos modos de aliança entre os irmãos, que a autora denomina de função fraterna. Kehl (p. 171) afirma que

Com frequência, nas famílias que se desfazem e refazem várias vezes ao longo da vida das crianças, os irmãos constituem referências sólidas para as identificações horizontais; alianças de afeto e cumplicidade entre os irmãos são mais estáveis do que os laços com os adultos.

Ao se pensar a família na lógica proposta pela autora (como tentacular), na qual as relações entre os irmãos são as que se mantêm mais estáveis, a responsabilidade de manutenção do ideal de família recairia mais sobre eles?

Bauman (2004, p. 59) afirma que "com a nova fragilidade das estruturas familiares, com a expectativa de vida de muitas famílias sendo mais curta do que a de seus membros, (...) um filho pode ser ainda 'uma ponte' para algo mais duradouro". Neste sentido, um filho é, antes de mais nada, um objeto de consumo emocional, esperando-se que ele proporcione alegrias e sirva a necessidades e desejos de seus pais.

O filho também significa a continuidade dos pais e um sentido para suas vidas. Desta forma, a boa relação entre irmãos - salientada como amizade no discurso dos entrevistados - pode ser a garantia buscada pelos pais para a manutenção da família idealizada. E nada mais resta aos pais que incentivar ao máximo a relação fraterna.

Um terceiro ponto a ser levantado é a relação dos entrevistados com seus irmãos. Se eles incentivam os filhos a serem amigos, essa prática nem sempre está presente em seus cotidianos. Apesar de não ter sido ponto de investigação mais aprofundada nas entrevistas, falou-se pouco dos irmãos e menos ainda foram as menções de amizade. Uma hipótese a ser levantada é o modelo da família de origem. Como os entrevistados vieram de famílias com organizações mais hierarquizadas, a amizade entre irmãos pode não ter sido valorizada em seu interior e, por isto, não ter se tornado uma prática mais corrente. 


\section{Considerações finais}

A família contemporânea tem trazido desafios para seus membros. Pela pluralidade em suas formas e flexibilidade em suas regras e desempenho de papéis, as relações familiares têm que ser reinventadas e negociadas cotidianamente. Estas reinvenções e negociações são atravessadas pelas contradições que os modelos hierárquico e igualitário trazem. Pais que foram criados em famílias primordialmente hierárquicas buscam educar seus filhos de forma mais igualitária.

A fragilidade que as famílias contemporâneas têm vivido pode ser compensada por um discurso e/ou uma prática que garanta a elas - pelo menos em fantasia ou intenção uma indissociabilidade. Por isto, diversas tentativas têm sido feitas. Uma destas tentativas, que segue uma lógica mais igualitária, parece ser pautada pelo discurso da amizade no interior da família, seja entre pais e filhos ou entre irmãos.

A fase da adolescência traz um desafio a mais para a família. Uma das tarefas desta fase é a construção de uma identidade adulta. Para tal, o jovem deve abandonar seus papéis infantis, o que implica abandonar um tipo de relação estabelecida com os pais. neste processo, ocorrem modificações na família que demandam adaptação e flexibilidade das regras.

Um problema que pode surgir neste momento, caso os pais assumam o lugar de amigos de seus filhos, é haver uma lacuna no lugar da figura da autoridade. Estabelecendo vínculos fraternizados, os adolescentes podem encontrar dificuldades no processo de construção de uma identidade adulta, pois não teriam com quem competir, a quem desafiar ou processar lutos considerados característicos dessa fase da vida.

Os pais entrevistados, apesar de tentarem sustentar o discurso da amizade, não parecem à vontade com suas possíveis repercussões no cotidiano. A amizade coloca em cena, e até em risco, sua autoridade frente aos filhos. Como esta também não é a referência que os pais tiveram enquanto filhos, falta-lhes um parâmetro para a relação com os próprios filhos. Por outro lado, o parâmetro que têm - relação hierárquica, mais distanciada e de pouco diálogo - já não é mais percebido como desejável pelos entrevistados. Fica o impasse de como resolver esta situação.

Outro problema que o discurso da amizade traz e que os entrevistados colocam é que a relação entre pais e filhos é mais forte, duradoura, presente em todos os momentos da vida; ou seja, é incondicional. Já a amizade é mais perene, fluida, apresentando mais riscos. Entretanto, a amizade parece garantir aos pais uma relação de maior proximidade e intimidade com os filhos. Também pode tamponar o processo de separação necessário na adolescência, que é tão difícil para os pais, como aparece nas entrevistas.

Parece que a grande questão em jogo é o estabelecimento e o formato das relações entre pais e filhos adolescentes. Por um lado, há o desejo de relações mais igualitárias e pautadas pelo modelo da amizade e, por outro, uma valorização da família tradicional e a necessidade de se manter o papel de pai/mãe marcado pela autoridade e pela diferença. A tensão entre ser amigo e manter uma relação paterno-filial toma dimensões diferenciadas de acordo com a situação vivida, havendo variações não só entre as famílias, mas também no interior de uma única família. Mais uma vez, pode-se pensar na convivência conflituosa de ambos os conjuntos de valores em uma mesma família, possibilitando pensar uma pluralidade de modelos e vivências familiares.

Enfim, como a tentativa dos pais parece ser de manter a família inquestionável, perdurando para sempre, resta a eles buscar soluções que lhes garantam tal desejo.

\section{Referências}

Allan, G. (1989). Friendship: Developing a sociological perspective. Boulder, CO: Westview.

Bauman, Z. (2004). Amor líquido (C. A. Medeiros, Trad.). Rio de Janeiro: Jorge Zahar.

Cicchelli, V. (2001). Repensar os laços entre pais e jovens adultos fora da aporia conflito/entendimento. Interseções: Revista de Estudos Interdisciplinares, 3(2), 247-265.

Coelho, S. V. (2007). Família contemporânea e a concepção moderna de criança e adolescente. In Instituto da Criança e do Adolescente (Org.), Criança e adolescente: Prioridade absoluta (pp. 189-228). Belo Horizonte: Ed. PUC-MG.

Costa, G. (1997). Conflitos da vida real. Porto Alegre: Artes Médicas.

Cucó, J. (1995). La amistad: Perspectiva antropológica. Barcelona, Espanha: Icaria.

Ferreira, A. B. H. (2009). Novo dicionário Aurélio da língua portuguesa. Curitiba: Positivo.

Friedlander, P. (1998). Theory, method and oral history. In R. Perks \& A. Thomson (Eds.), The oral history reader (pp. 311-319). London: Routledge.

Heilborn, M. L. (2004). Dois é par. Rio de Janeiro: Garamond.

Houaiss, A. (2009). Dicionário Houaiss da língua portuguesa. Rio de Janeiro: Objetiva.

Kehl, M. R. (2003). Em defesa da família tentacular. In G. C. Groeninga \& R. C. Pereira (Orgs.), Direito e psicanálise: Rumo a uma nova epistemologia (pp. 163-176). Rio de Janeiro: Imago.

Laville, C., \& Dionne, J. (1999). A construção do saber: Manual de metodologia da pesquisa em ciências humanas (H. Monteiro \& F. Settineri, Trads.). Porto Alegre: Artes Médicas; Belo Horizonte: Ed. UFMG.

Macedo, M. M. K., Azevedo, B. H., \& Castan, J. U. (2004). Adolescência e psicanálise. In M. M. K. Macedo (Org.), Adolescência e psicanálise: Interseções possíveis (pp. 13-64). Porto Alegre: Ed. PUC-RS.

Machado, M. N. M. (2002). Entrevista de pesquisa: A interação pesquisador/entrevistado. Belo Horizonte: C/Arte. 
Oliveira, I. M. D. A. (2000). De quem é o vestibular? A mãe frente à diferenciação do filho. Dissertação de Mestrado não-publicada, Universidade Católica de Pernambuco, Recife.

Paine, R. (1974). An exploratory analysis of middle-class culture. In E. Leyton (Ed.), The compact: Selected dimensions of friendship (pp. 1-14). Newfoundland: Memorial University of Newfoundland.

Peck, J. S., \& Manocherian, J. R. (1995). O divórcio nas mudanças do ciclo de vida familiar. In B. Carter \& M. McGoldrick (Orgs.), As mudanças no ciclo de vida familiar: Uma estrutura para a terapia familiar (M. A. V. Veronese, Trad., pp. 291-320). Porto Alegre: Artes Médicas.

Pollak, M. (1989). Memória, esquecimento, silêncio. Estudos Históricos, 2(3), 3-15.

Pratta, E. M. M., \& Santos, M. A. (2007). Opiniões de adolescentes do ensino médio sobre o relacionamento familiar e seus planos para o futuro [Versão eletrônica]. Paidéia (Ribeirão Preto), 17(36), 103-114. Recuperado em 20 março 2009, de http://www.scielo.br/pdf/paideia/ v17n36/v17n36a10.pdf

Rezende, C. B. (2001). Amigos como irmãos e pais amigos: A interseção de categorias e valores em um discurso carioca. Interseções: Revista de Estudos Interdisciplinares, 3(2), 199-212.

Rezende, C. B. (2002). Os significados da amizade: Duas visões de pessoa e sociedade. Rio de janeiro: Ed. FGV.

Roudinesco, E. (2003). A familia em desordem (A. Telles, Trad.). Rio de Janeiro: Jorge Zahar.

Singly, F. (2000). O nascimento do indivíduo individualizado e seus efeitos na vida conjugal e familiar. In C. E. Peixoto, F. Singly, \& V. Cicchelli (Orgs.), Família e individualização (pp. 13-19). Rio de Janeiro: Ed. FGV.

Singly, F. (2007). Sociologia da família contemporânea (C. E. Peixoto, Trad.). Rio de Janeiro: Ed. FGV.

Stengel, M. (2000). Adolescência: Uma perspectiva psicossocial. Psicologia em Revista 1(10), 44-52.

Stengel, M. (2003). Obsceno é falar de amor? As relações afetivas dos adolescentes. Belo Horizonte: Ed. PUCMG.

Vaitsman, J. (1994). Flexiveis e plurais: Identidade, casamento e família em circunstâncias pós-modernas. Rio de Janeiro: Rocco.

Vala, J. (1986). A análise de conteúdo. In A. S. Silva \& J. M. Pinto (Orgs.), metodologia das ciências sociais (pp. 101128). Porto, Portugal: Edições Afrontamento.

Márcia Stengel é Professora Adjunta da Faculdade de Psicologia da Pontifícia Universidade Católica de Minas Gerais. 